\title{
ESTUDO DA VIABILIDADE DA LEVEDURA Saccharomyces cerevisiae Y904 EMPREGANDO PROCESSO FERMENTATIVO EM BATELADA REPETIDA
}

\author{
M. L. CRUZ ${ }^{1}$; F.T.M. SILVA ${ }^{1}$; M. L. F. RAMINHO ${ }^{1}$; A. L. M. CASTRO ${ }^{1}$; \\ M. M. RESENDE ${ }^{1}$ E. J. RIBEIRO ${ }^{1}$ \\ ${ }^{1}$ Universidade Federal de Uberlândia, Faculdade de Engenharia Química. \\ E-mail para contato: mariana_lopes10@hotmail.com
}

\begin{abstract}
RESUMO - Na produção do etanol empregando mostos formados de caldo de cana e melaço oriundo da fabricação de açúcar, após a etapa da fermentação, o fermento é separado do vinho fermentado e reciclado para ser novamente utilizado em novas fermentações. O aumento do teor alcoólico do vinho a valores acima de $10 \%$ (v/v) pode diminuir a viabilidade do fermento, chegando a inviabilizar o reciclo das leveduras. Neste trabalho avaliou-se o crescimento da levedura Saccharomyces cerevisiae $Y 904$ a $20^{\circ} \mathrm{C}$, sua viabilidade celular e sua reutilização em processos de fermentação em batelada repetida. Verificou-se que para fermentações em batelada repetida, conduzidas a $20^{\circ} \mathrm{C}$, empregando uma concentração inicial de sacarose de $180 \mathrm{~g} / \mathrm{L}$, após a terceira fermentação, o teor alcoólico chegou a $12 \%$ (v/v), com um rendimento acima de $90 \%$, com uma viabilidade celular de $92 \%$, indicando ser possível o reciclo celular para fermentações com teor alcoólico mais elevado.
\end{abstract}

\section{INTRODUÇÃO}

Os biocombustíveis por serem oriundos de fontes renováveis, contribuem para redução da emissão de poluentes, já que grande parte dos gases resultantes da sua queima é reabsorvida nos ciclos de crescimento das plantas (NOGUEIRA e CAPAZ, 2013; DIAS et al., 2013). Dentre os vários combustíveis de fontes renováveis existentes, tem-se o etanol, que é considerado um combustível ecológico, uma vez que ele é obtido a partir de fontes renováveis cuja fonte principal, no Brasil, é a cana-de-açúcar. Também é ecológico porque contribui para a redução de $\mathrm{CO}_{2}$ na atmosfera através da fotossíntese realizada pela fonte vegetal. Além de etanol e $\mathrm{CO}_{2}$, vários subprodutos são produzidos durante a fermentação alcoólica. Um dos principais subprodutos é o glicerol. Ele é produzido a um nível de 1,0\% (v/v) para a maioria dos processos de fermentação alcoólica. Outros subprodutos como ácidos orgânicos e alcoóis superiores são produzidos em níveis muito mais baixos (COSTA e SODRÉ, 2010).

Apesar de esforços visando à utilização de outros microrganismos para a obtenção de etanol em destilarias brasileiras, a utilização da Saccharomyces cerevisiae continua sendo a mais adequada, pois se trata de processos não estéreis necessitando de leveduras robustas. Além disso, ela se destaca pela alta eficiência fermentativa, um crescimento rápido, habilidade na produção de etanol e consumo de sacarose, tolerância a altas concentrações de etanol e a baixos níveis de 


\section{9 a 22 de outubro de 2014 \\ Florianópolis/SC}

oxigênio, osmotolerância e tolerância a grandes variações de temperaturas (ANDRIETTA et al., 2007).

No que diz respeito às células de leveduras, elas necessitam de condições nutricionais durante o processo de fermentação alcoólica, o que influencia diretamente na multiplicação celular e na eficiência da transformação do açúcar em etanol (RIBEIRO et al., 1987). Temperaturas elevadas afetam o comportamento da levedura e diminuem o teor alcoólico do mosto, além de contribuir para a multiplicação bacteriana. Com o aumento da temperatura a toxidez do etanol sobre o fermento é intensificada, causando perda de viabilidade celular e causando baixo rendimento (AMORIM, BASSO e ALVES, 1996; SANTOS, 2008). A viabilidade é um fator importante para a fermentação alcoólica. Quanto maior for a viabilidade celular, melhor será o desempenho do processo. Na literatura foi observado que a viabilidade celular diminui continuamente em anaerobiose, mas permanece acima de $95 \%$ em aerobiose num sistema de fermentação a vácuo. $\mathrm{O}$ aumento da temperatura de fermentação produz uma forte diminuição da viabilidade celular, devido ao aumento das taxas de produção e acúmulo de etanol no meio e nas células (STECKELBERG, 2001). A temperatura adequada deve ser mantida na fermentação por meio de dispositivos para o resfriamento de dornas. À medida que a temperatura aumenta, a contaminação bacteriana é favorecida e a levedura fica mais sensível à toxidez do etanol. As linhagens industriais de $S$. cerevisiae são normalmente resistentes à alta temperatura, mas este fator interfere na viabilidade celular quando em sinergia com a presença de etanol ou meio com baixo $\mathrm{pH}$ (SILVA FILHO et al., 2005). O rendimento alcoólico é maior em temperaturas mais baixas $\left(15\right.$ a $\left.20^{\circ} \mathrm{C}\right)$, porém apresentam uma demora para a obtenção da produção máxima. Quando a temperatura do biorreator é de $25^{\circ} \mathrm{C}$ a $31^{\circ} \mathrm{C}$ a taxa inicial de fermentação é maior, mas em temperaturas maiores que $35^{\circ} \mathrm{C}$ decresce a viabilidade celular (TORIJA et al., 2003). O glicerol, juntamente com o ácido succínico, são os principais subprodutos da fermentação alcoólica e são responsáveis pela redução do rendimento em etanol, pois consomem 3-5\% dos açúcares fermentáveis (GANCEDO e SERRANO, 1989).

As fermentações conduzidas a temperaturas mais baixas podem levar a uma maior resistência da levedura no teor de etanol final e também um menor geração de subprodutos do metabolismo celular devido à menor tensão à qual as células são submetidas. Assim, o objetivo deste trabalho foi avaliar a viabilidade da levedura Saccharomyces cerevisiae empregando processo fermentativo em batelada repetida na temperatura de $20^{\circ} \mathrm{C}$.

\section{MATERIAL E MÉTODOS}

Os ensaios experimentais foram realizados em batelada repetida, em um minifermentador, modelo New Brunswick Multigen equipado com controle de temperatura e de agitação. O volume do inóculo correspondeu a $30 \%$ do volume total do meio. O volume total de cada fermentação foi $1,5 \mathrm{~L}$, sendo $0,45 \mathrm{~L}$ de inóculo. $\mathrm{O}$ inóculo consistiu-se da levedura após hidratação em água durante 2 horas, sob agitação. A levedura Saccharomyces cerevisiae utilizada neste trabalho foi a cepa industrial Y -904 produzida pela ABB Brasil . A composição 
do meio de cultura para as leveduras consistia em sacarose (180 g/L), $\mathrm{KH}_{2} \mathrm{PO}_{4}(5 \mathrm{~g} / \mathrm{L}), \mathrm{MgSO}_{4} \cdot 7$ $\mathrm{H}_{2} \mathrm{O}(1 \mathrm{~g} / \mathrm{L}), \mathrm{NH}_{4} \mathrm{Cl}(1,5 \mathrm{~g} / \mathrm{L}), \mathrm{KCl}(1 \mathrm{~g} / \mathrm{L})$ e extrato de levedura $(6 \mathrm{~g} / \mathrm{L})$. Os reagentes utilizados foram todos de grau analítico, exceto a sacarose, a qual foi substituída por açúcar cristal comercial. $\mathrm{O}$ pH inicial de todas as fermentações realizadas foi 4,5.

As concentrações de açúcares (sacarose, glicose e frutose), etanol e glicerol em todos os experimentos foram determinadas por cromatografia líquida de alto desempenho (HPLC).

Para determinação da concentração celular no início e final das fermentações, utilizou-se uma câmara de Neubauer espelhada e um microscópio óptico (Olympus). Para a contagem das células, diluiu-se a amostra e promoveu-se a homogeneização com uma vigorosa agitação. Colocou-se esta solução, com o auxílio de uma pipeta Pasteur, entre a câmara de Neubauer e a lamínula, previamente limpas com álcool 70\%. Realizou-se a contagem das células em microscópio óptico utilizando-se um aumento de 100 vezes. O cálculo da concentração de célula foi realizado de acordo com a Equação 1 (MADIGAN et al., 2004).

$$
\text { células }(\text { células } / \mathrm{mL})=\frac{\mathrm{n}^{\circ} \text { células totais } \times \frac{1}{\text { volume do retículo }} \times \text { diluição }}{\mathrm{n}^{\circ} \text { retículos }} \times 1000
$$

Para acompanhar o crescimento celular ao longo das fermentações, foi utilizado o método espectrofotométrico. Diluiu-se na proporção 1:100 o meio fermentativo e leu-se a absorbância em espectrofotômetro a $650 \mathrm{~nm}$. Esse valor lido era comparado com uma curva padrão que relaciona absorbância com concentração celular em termos de massa seca em gramas por litro, previamente determinada.

\section{RESULTADOS E DISCUSSÃO}

A Figura 1 mostra os perfis de concentração de sacarose, etanol e concentração celular na primeira fermentação conduzida a $20^{\circ} \mathrm{C}$, em batelada com concentração inicial de $180 \mathrm{~g} / \mathrm{L}$ de sacarose e inoculo de $30 \%$ v/v, sem qualquer adaptação da levedura nesta temperatura.

Após 49 horas de fermentação, o teor alcoólico atingiu 9,70 ${ }^{\circ} \mathrm{GL}$ com um rendimento em etanol de $83,3 \%$. A concentração celular que no início desta primeira fermentação era de 2,38 $\mathrm{g} / \mathrm{L}$ subiu para $8,93 \mathrm{~g} / \mathrm{L}$ no final da fermentação, onde obteve-se viabilidade de $91,89 \%$. 


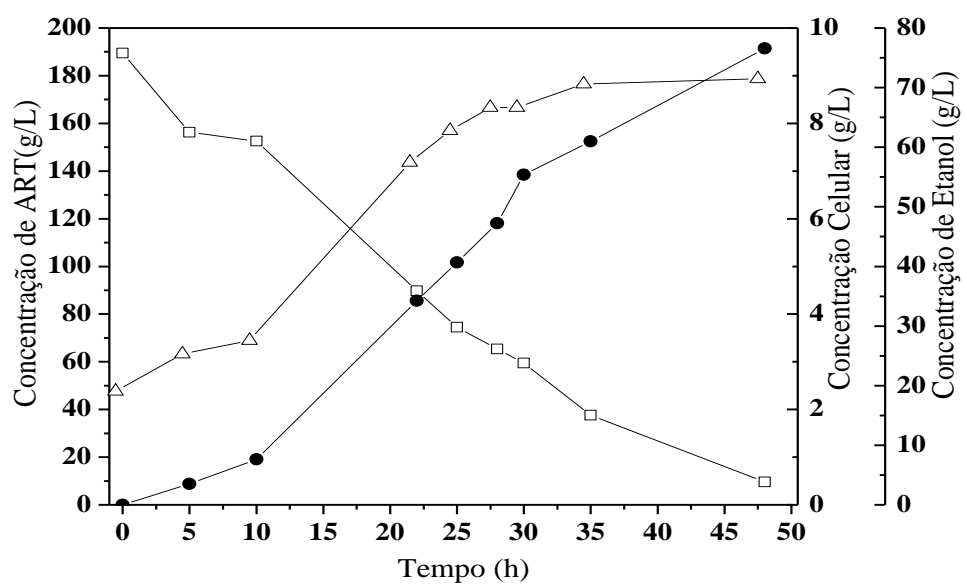

Figura 1 - Perfis de concentração de açúcar redutor total - ART ( ๖), concentração de etanol (•) e concentração celular $(\Delta)$ em função do tempo, para a $1^{\text {a }}$ fermentação realizada a $20^{\circ} \mathrm{C}$.

Reutilizando a levedura da primeira fermentação, foi realizada uma segunda fermentação nas mesmas condições experimentais da primeira, cujos resultados são apresentados na Figura 2. Com 32 horas de fermentação a concentração de sacarose residual era de aproximadamente 4 $\mathrm{g} / \mathrm{L}$, o teor alcoólico de $10,9^{\circ} \mathrm{GL}$ com um rendimento de $91,2 \%$, obtendo-se uma melhoria em todos os parâmetros em relação à primeira fermentação. A concentração celular também aumentou de 7 para $13 \mathrm{~g} / \mathrm{L}$ e a viabilidade celular foi de $91,94 \%$, praticamente o mesmo valor daquele da primeira fermentação.

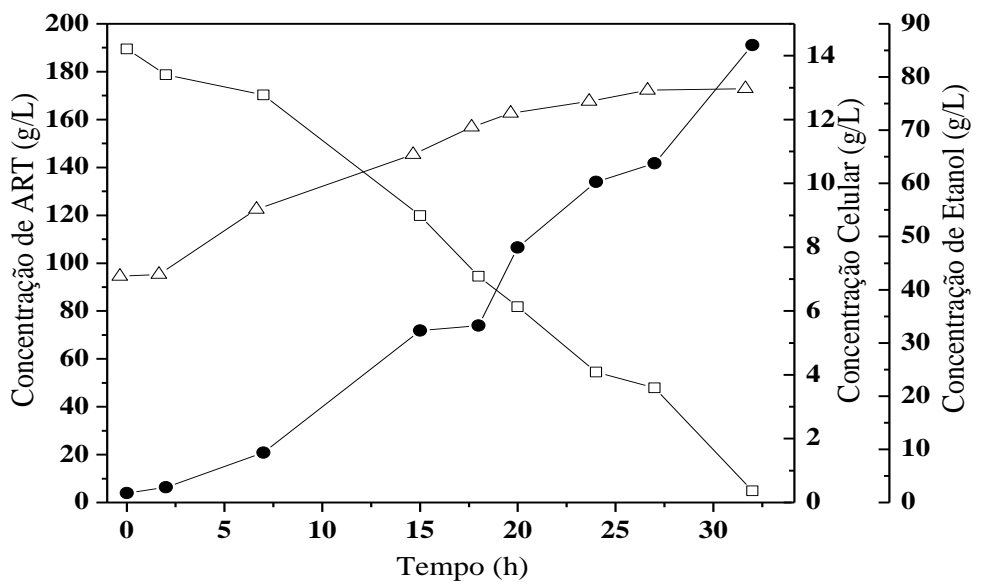

Figura 2 - Perfis de concentração de açúcar redutor total- ART ( (), concentração de etanol $(\bullet)$ e concentração celular $(\Delta)$ em função do tempo, para a $2^{\mathrm{a}}$ Fermentação realizada a $20^{\circ} \mathrm{C}$. 
Realizou-se uma terceira fermentação a $20^{\circ} \mathrm{C}$, recuperando e reutilizando a levedura centrifugada da segunda fermentação, cujos resultados estão apresentados na Figura 3. Com um tempo de fermentação de 26 horas, o teor alcoólico alcançou $11,94{ }^{\circ} \mathrm{GL}$ com um rendimento de $93,33 \%$ e consumo praticamente total do açúcar. A viabilidade celular ao final da fermentação foi de $92 \%$.

$\mathrm{Na}$ sequência do trabalho, foram realizadas sucessivas fermentações nas mesmas condições experimentais das anteriores, recuperando e reutilizando o fermento centrifugado. Foi possível chegar ao teor alcoólico de aproximadamente $12 \%$, indicando a possibilidade de se trabalhar com maior teor de etanol no mosto e reciclagem de leveduras, já que a viabilidade se manteve elevada e praticamente constante, em torno de 92\%, mesmo depois de sucessivas repetições. Estes resultados foram bastante satisfatórios em relação ao teor alcoólico, rendimento em etanol e viabilidade celular mantidos após os sucessivos reaproveitamentos da levedura. $\mathrm{O}$ tempo de fermentação, a $20^{\circ} \mathrm{C}$ ainda é elevado se comparado com os atuais tempos de fermentação obtidos em batelada alimentada nas destilarias brasileiras. Um aspecto importante a ser destacado é a possibilidade de reciclar a levedura mesmo com teores alcoólicos acima de $10^{\circ} \mathrm{GL}$.

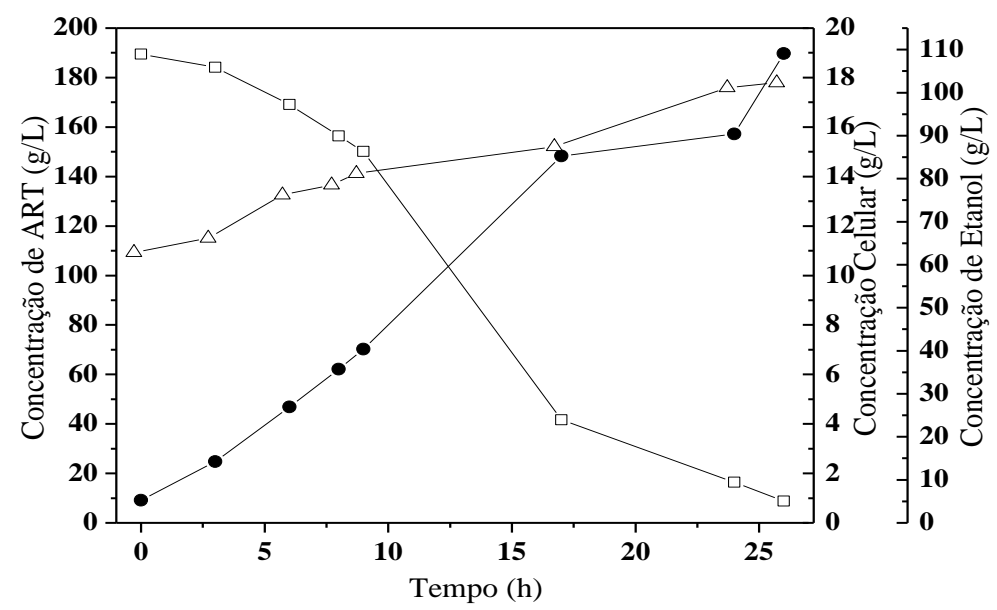

Figura 3 - Perfis de concentração de açúcar redutor total - ART ( $\square)$, concentração de etanol (•) e concentração celular $(\Delta)$ em função do tempo, para a $3^{\mathrm{a}}$ Fermentação realizada a $20^{\circ} \mathrm{C}$.

O aumento de $2 \%$ do teor alcoólico observado da primeira para a terceira fermentação foi bastante significativo. Segundo dados publicados amplamente pela literatura, a cada $1 \%$ de aumento no teor alcoólico obtido no vinho fermentado, é obtida uma redução de 15 bilhões de litros de vinhaça por ano considerando todas as usinas do Brasil. O tempo de fermentação também é extremamente vantajoso comparado ao etanol de milho, já que na última dura 70 horas e no etanol de cana foram necessárias apenas 26 horas na temperatura de $20^{\circ} \mathrm{C}$, que não é a considerada ótima para a levedura. 


\section{CONCLUSÃO}

Com os resultados obtidos até agora com a cepa Saccharomyces cerevisiae Y904 é possível concluir que, nos processos de fermentação a temperaturas mais baixas, a resistência ao etanol é maior. Outro aspecto evidenciado é a viabilidade que se manteve praticamente constante ao longo das fermentações conduzidas a $20^{\circ} \mathrm{C}$.

\section{AGRADECIMENTOS}

Os autores agradecem a Universidade Federal de Uberlândia e a Faculdade de Engenharia Química pela oportunidade em realizar este trabalho. Agradecem também ao apoio financeiro da CAPES, FAPEMIG e do CNPq.

\section{REFERÊNCIAS BIBLIOGRÁFICAS}

AMORIN, H.V., BASSO, L.C., ALVES, D.M.G. Processos de produção de álcool - Controle e monitoramento, Fementec/FEALQ/ESALQ- USP, Piracicaba, São Paulo, 103 p, 1996.

ANDRIETTA, M.G.S, ANDRIETTA, S.R.; STECKELBERG, C.; STUPIELLO, E.N.A.. Bioetanol - 30 years of Proálcool. International Sugar Journal, Campinas, v.109, n. 1299, p. 195-200, 2007.

COSTA, R.C.; SODRÉ, J.R.. Hydrous ethanol vs. gasoline-ethanol blend: Engine performance and emissions. Fuel v. 89, p. 287-293, 2010.

DIAS, M. O.S.; JUNQUEIRAA, T.L.; CAVALETTA, O.; CUNHA, M. P.; JESUS, C.D.F,; MANTElATTOA, P. E.; ROSSEllA, C. E. V.; FILHO, R. M.; BONOMIA, A. Cogeneration in integrated first and second generation ethanol from sugarcane. Chemical engineering research and design v. 91, p. 1411-1417, 2013.

GANCEDO, C.; SERRANO, R. Energy - yielding metabolism. In: Rose A. H., Harrison J. S. (eds) The yeasts. Metabolism and Physiology of Yeast, Academic, London, p. 205 - 259, 1989.

MADIGAN, M.T.; MARTINKO, J.M.; PARKER, J. Microbiologia de Brook, 10. ed. São Paulo, Brasil: Prentice Hall, 2004. 
RIBEIRO, F.J., LOPES, J.J.C., FERRARI, S.E.. Complementação de nitrogênio de forma contínua no processo de fermentação alcoólica, Brasil Açucareira, v.105, n.1, p. 26-30, 1987.

SANTOS, A. M. Fermentação alcoólica com levedura imobilizada em colmos de bambu e em fibra de coco. 82 p. Dissertação (Mestrado em Engenharia Química) - Pós Graduação em Engenharia Química, Universidade Federal de Alagoas, Maceió, 2008.

SILVA-FILHO, E. A.; SANTOS, S. K. B.; RESENTE, A. M.; MORAIS, J. O. F.; MORAIS JR, M. A.; SIMÕES D. A.. Yeast population dynamics of industrial fuel-ethanol fermentation process assessed by PCR-fingerprinting. Antonie van Leeuwenhock, v. 88, p. 13-23, 2005.

STECKELBERG, C. Caracterização de leveduras de processos de fermentação alcoólica utilizando atributos de composição celular e características cinéticas. Tese (Doutorado em Engenharia Química). Faculdade de Engenharia de Química,Universidade Estadual de Campinas. 215p., 2001.

TORIJA, M.J.; ROZÈS, N.; POBLET, M.; GUILLAMÓN, J.M. MAS, A. Effects of Fermentation Temperature on the Strain Population of Saccharomyces cerevisiae. International Journal of Food Microbiology, v.80, p.47,53, 2003. 